\title{
Trimethoprim-sulphamethoxazole (Septrin) in the treatment of rectal gonorrhoea
}

\author{
M. A. WAUGH \\ West London Hospital, Charing Cross Hospital Group
}

The recent increase in some parts of London of syphilis acquired homosexually (Lancet, 1964; Brit. med. F., 1967) has indicated that a drug of nontreponemicidal properties is to be preferred in the treatment of gonococcal proctitis in homosexual men. Septrin was considered as a potentially useful remedy in these circumstances. Though taken orally and so subject to error or misuse, it needs be taken only twice daily for a short time.

Men with rectal gonorrhoea are among some of the most conscientious patients at the clinic, if handled sympathetically from the start; in the West and South-west districts of London they are mostly aware of the dangers of venereal infection and so far as can be judged are to be trusted with oral therapy.

\section{Septrin}

Septrin (Burroughs Wellcome \& Co) consists of trimethoprim $80 \mathrm{mg}$. and sulphamethoxazole $400 \mathrm{mg}$. (Tudhope, 1969). Trimethoprim is a powerful inhibitor of dihydrofolic acid reductase, the enzyme which catalyses the conversion of dihydrofolic to tetrahydrofolic acid. This follows the conversion of para-amino benzoic acid to dihydrofolic acid, the stage at which sulphonamides block the synthesis of purines in bacteria.

Trimethoprim and sulphamethoxazole act synergestically with bactericidal effect.

Trimethoprim is absorbed rapidly when taken orally and is excreted in high concentrations in the urine. Bacterial resistance to it develops rapidly but combination with a sulphonamide reduces the development of resistant strains to each drug. The combination is also rapidly absorbed by the oral route. High plasma levels are reached within 2 to 4 hours and are maintained for over 12 hours.

Side-effects in the case of trimethoprim are those of interference with folic acid metabolism; granulocytopenia and thrombocytopenia have been reported by Mohan (1969). Septrin should not be given to a patient sensitive to sulphonamides because of the sulphamethoxazole moiety.

Csonka and Knight (1967) have shown trimethoprim and sulphamethoxazole to be successful in 89 to 93 per

Received for publication March 17, 1970 cent. of cases of gonococcal urethritis. The good results with this combined agent in infections which had failed to respond to penicillin or tetracycline is noteworthy as it indicates an absence of cross resistance, so far.

\section{Diagnosis, treatment and follow-up}

The diagnosis of gonococcal proctitis was based on finding typical Gram-negative diplococci in pus cells, present in rectal smears.

Having been instructed to take two Septrin tablets each morning and two each evening, for 7 days, the patients were asked to return between 1 and 4 days later, when further proctoscopy was carried out and repeat rectal smears, stained by Gram's method, were scrutinized for the presence of gonococci. Thereafter the patient was re-examined at weekly intervals. Blood was taken on the first visit for serum tests for syphilis which were repeated a month later.

\section{Case material}

72 patients entered the trial but eight were later omitted because follow-up could not be secured. Final results were assessed on 66 cases from 64 patients, one subject born in the United Kingdom having three attacks, all included in the series. The ages of the patients ranged from 15 to 48 years (mean 27.7).

There were 49 patients born in the United Kingdom, three in Eire, two in the United States of America, two in India (one of European descent), one in South Africa and one in Zambia (both of European descent), and one each in New Zealand, Brazil, Germany, Netherlands, Spain, and Yugoslavia. Sixty of the patients were single, two were married, and two were separated.

A history of previous venereal diseases was given by 44 patients ( 65 per cent.).

\section{Results}

Treatment failure, as defined by Dallas (1958) was deemed to have occurred if gonococci were found in the smears between 1 and 14 days after treatment, there having been no history of subsequent exposure 
to infection. The 64 patients who suffered 66 attacks of proctitis made an average of 2.9 follow-up visits, and the average duration of attendance after the initial visit was 27 days. Treatment failure was diagnosed in eight cases-a failure rate of $12 \cdot 1$ per cent. One patient developed urticaria after treatment.

\section{Discussion}

Using a dosage of 600,000 units procaine penicillin, Scott and Stone (1966) diagnosed thirteen cases of treatment failure in 36 patients treated-a 43 per cent. failure rate. Evans (1966), using the same dose, reported a failure rate of 20.5 per cent. in 83 patients. Fluker and Boulton-Hewitt (1970) reported two series each of 100 cases of gonococcal proctitis treated with procaine penicillin $1.8 \mathrm{~m}$.u. and kanamycin $2 \mathrm{~g}$. respectively; treatment failure was seen in 27.1 per cent. of those treated with procaine penicillin and in 15.5 per cent. of those treated with kanamycin. The results achieved in the present series using Septrin compare well with those of Fluker and Boulton-Hewitt using kanamycin and are superior to those achieved with penicillin.

\section{Summary}

A series of 66 cases of gonococcal proctitis in homo- sexual men attending Luke Clinic, West London Hospital, was treated with trimethoprim-sulphamethoxazole (Septrin) two tablets twice daily for 7 days. The failure rate was $12 \cdot 1$ per cent. This compares favourably with results from other methods of treating rectal gonorrhoea, and Septrin has the advantage of not masking concomitant syphilis.

I should like to thank Dr. J. L. Fluker for his helpful advice throughout this study and in the preparation of this paper.

\section{References}

Brit. med. F. (1967) Leader, 2, 5

CsonkA, G. W., and KNIGHT, G. J. (1967) Brit. f. vener. Dis., 43, 161

DaLlas, N. L. (1958) Ibid., 34, 194

Evans, A. J. (1966) Ibid., 42, 251

FlukeR, J. L., and Boulton-Hewitt, A. (1970) Ibid., 46, 454

Lancet (1964) Leader, 1, 481

Mohan, P. (1969) Practitioner, 202, 553

Scott, J., and Stone, A. H. (1966) Brit. F. vener. Dis. 42, 103

Tudhope, G. R. (1969) Practitioner, 203, 405 